\title{
POSITIVE AND NEGATIVE SYMPTOMS COVARY DURING CLOZAPINE TREATMENT IN SCHIZOPHRENIA
}

\author{
Rajiv Tandon, Robert Goldman, John R. DeQuardo, Mona Goldman, \\ Melinda Perez and Michael Jibson \\ Schizophrenia Program, University of Michigan Medical Center, Ann Arbor, MI 48109-0116, U.S.A
}

(Received for publication 3 November 1993)

\begin{abstract}
Summary - Although negative symptoms were traditionally considered to be unresponsive to neuroleptic medication, recent studies have demonstrated that negative symptoms do improve during neuroleptic treatment and that such improvement tends to occur concurrently with improvement in positive symptoms. Clozapine is an atypical neuroleptic that is effective in a significant proportion of otherwise neuroleptic-nonresponsive schizophrenic patients; in contrast to conventional neuroleptics, clozapine is also purported to possess unique efficacy in the amelioration of negative symptoms. How clozapine-associated reduction in negative symptoms relates to change in positive symptoms is not clear. To study the relationship between change in positive and negative symptoms during clozapine treatment, we monitored symptomatology in 40 DSM-III-R schizophrenic patients before and about 8 weeks after a trial of clozapine. Both positive and negative symptoms improved significantly. There was a significant correlation $(r=.63, p<.01)$ between change in positive symptoms and change in negative symptoms; as with conventional neuroleptics, negative symptoms improved concomitantly with positive symptoms during clozapine treatment. Clozapine's apparent greater efficacy on negative symptoms may be related to its greater efficacy on positive symptoms in otherwise neuroleptic-refractory patients and its lesser propensity to cause extrapyramidal sideeffects.
\end{abstract}

\section{Introduction}

AlthOUGH negative schizophrenic symptoms have traditionally been considered to be poorly responsive to neuroleptic treatment (Crow, 1980; Andreasen et al., 1982), several recent studies have demonstrated that negative symptoms do improve in the course of neuroleptic treatment of schizophrenic patients (Breier et al., 1987; van Kammen et al., 1987; Meltzer, 1990; Tandon et al., 1990; Tandon et al., 1993). Furthermore, this improvement in negative symptoms has been found to occur concomitantly with improvement in positive symptoms (van Kammen et al., 1987; Meltzer, 1990; Tandon et al., 1990; Tandon et al., 1993); with conventional neuroleptic treatment, improvement in negative symptoms generally does not occur independently of improvement in positive symptoms.

Clozapine is an atypical antipsychotic agent with a unique therapeutic profile (Kane et al., 1988; Lader, 1992): in contrast to conventional neuroleptics, clozapine is more effective

Presented at the 48th annual meeting of the Society of Biological Psychiatry, San Francisco, 21 May, 1993. 
in decreasing positive and negative symptoms in treatment-refractory schizophrenic patients and causes fewer extrapyramidal side-effects (EPS) and tardive dyskinesia. It has been found to produce greater improvement in negative symptoms than typical neuroleptics (Kane et al., 1988; Meltzer, 1992). Meltzer (1990, 1991) observed that negative symptoms improved independently of change in positive symptoms in schizophrenic patients treated with clozapine; he noted that clozapine differed from conventional neuroleptics in this regard. The question of whether the observed greater efficacy of clozapine in treating negative symptoms is related to its greater efficacy in treating positive symptoms in this population of schizophrenic patients or whether the clozapine-associated reduction in negative symptoms occurs independently of such improvement has obvious pathophysiological and clinical importance. To study this question, we assessed positive and negative symptoms in a sample of 40 schizophrenic patients before and about 8 weeks after an open clinical trial of clozapine.

\section{Materials and Methods}

The sample consisted of 40 schizophrenic patients who received a clinical trial of clozapine for a minimum of 8 weeks. Patients were recruited from the University of Michigan Schizophrenia Program, principally through its affiliation with the Lenawee County Community Mental Health Center. Diagnostic evaluation included an extensive history, review of all clinical records, clinical observations, and a structured interview using the Schedule for Affective Disorders and Schizophrenia (SADS; Endicott and Spitzer, 1978). All patients met both DSM-III-R criteria (APA, 1987) and Research Diagnostic Criteria (RDC, Spitzer et al., 1978) for schizophrenia. The final sample of 40 patients consisted of 28 men and 12 women with a mean $\pm S D$ age of $37 \pm 10$ years and a mean duration of illness of $13 \pm 8$ years.

Patients were on treatment with one of several different neuroleptics prior to beginning treatment with clozapine. All but four were on treatment with either haloperidol, fluphenazine, or thiothixene with/without anticholinergic medication prior to starting treatment with clozapine; no patient was on a depot neuroleptic. Of the 44 patients who started the clozapine trial, 4 dropped out before 8 weeks because of intolerable side-effects. Clozapine was started on an inpatient basis in about half the patients and on an outpatient basis in the other half. Clinically-determined treatment-refractoriness was the principal reason for the clozapine trial in this group of patients. A titration protocol was utilized to gradually increase the dose of clozapine to $300 \mathrm{mg} /$ day generally by the end of the second week of the trial (although a slower titration was utilized in some patients). Patients were generally tapered off their previous neuroleptic over a period of 1-3 weeks as their dosage of clozapine was being titrated upwards. Clinicians were permitted to modify the dose of clozapine based on clinical response and the patient's ability to tolerate the medication. At the end of 8 weeks, the mean $\pm S D$ dose of clozapine was $405 \pm 120 \mathrm{mg}$ per day.

Baseline clinical ratings were performed 1-3 days before patients received their first dose of clozapine. Except for one patient who was drug-free, all others were receiving some neuroleptic at this timepoint. About 8 weeks after beginning treatment with clozapine (range $=8-10$ weeks), patients received another set of clinical ratings. Patients were rated 
on the Brief Psychiatric Rating Scale (BPRS, Overall \& Gorham, 1962) and the Scale for the Assessment of Negative Symptoms (SANS, Andreasen, 1983) at both timepoints. Assessment of global severity was made by the 18-item BPRS total score. Positive symptoms were assessed by the sum of the following four BPRS items: conceptual disorganization, suspiciousness, hallucinatory behavior, and unusual thought content; this cluster of BPRS items was utilized to define "key" positive symptoms in the pivotal multicenter clinical trial of clozapine in treatment-refractory schizophrenia (Kane et al., 1988). Negative symptoms were assessed by the SANS sum of global scores.

Paired two-tailed students' $t$-tests were performed to compare the symptom ratings at baseline to those eight weeks after initiating clozapine treatment. Correlation analysis (using Pearson product-moment correlations) between change in positive symptoms and change in negative symptoms was conducted to evaluate the covariance of these symptom clusters.

\section{Results}

Both positive and negative symptoms improved significantly $(\mathrm{p}<.01)$ with clozapine treatment (Table 1). Use of the BPRS “ANER" factor (emotional withdrawal, motor Table 1

Positive and Negative Symptom Ratings at Baseline and Following 8 Weeks of Treatment With Clozapine $(\mathrm{N}=40)$

\begin{tabular}{lcccc}
\hline & Baseline & Post-treatment & Significance & $\begin{array}{c}\text { Degree of } \\
\text { improvement } \\
\text { (\%) change } \\
\text { from baseline) }\end{array}$ \\
\hline $\begin{array}{l}\text { Global severity } \\
\text { (BPRS total) }\end{array}$ & $53.5 \pm 9.8$ & $43.3 \pm 9.2$ & $p<.01$ & $19.1 \%$ \\
$\begin{array}{l}\text { Positive symptoms } \\
\text { (BPRS “THOT") }\end{array}$ & $16.0 \pm 3.6$ & $12.4 \pm 3.5$ & $p<.01$ & $22.5 \%$ \\
$\begin{array}{l}\text { Negative symptoms } \\
\text { (SANS sum of global scores) }\end{array}$ & $13.8 \pm 4.5$ & $11.0 \pm 4.1$ & $p<.01$ & $20.3 \%$ \\
\hline
\end{tabular}

retardation, and blunted affect) instead of the SANS sum of global scores to define negative symptoms did not alter the findings. Change in negative symptoms was significantly correlated to change in positive symptoms (Fig. 1).

\section{Discussion}

In agreement with findings of other studies, these data confirm that both positive and negative schizophrenic symptoms improve significantly over the course of clozapine treatment. The significant correlation between change in positive and negative symptoms during clozapine treatment noted in this study is similar to the pattern observed with conventional neuroleptics. The correlated improvement in positive and negative symptoms during 8weeks clozapine treatment suggests that mechanisms underlying such improvement are linked, although it is conceivable that completely unrelated mechanisms (with similar time courses) may underlie improvement in positive and negative symptoms associated with clozapine treatment. It should be noted that the baseline from which change in positive and negative symptoms was assessed was not medication-free as patients were on some typical 


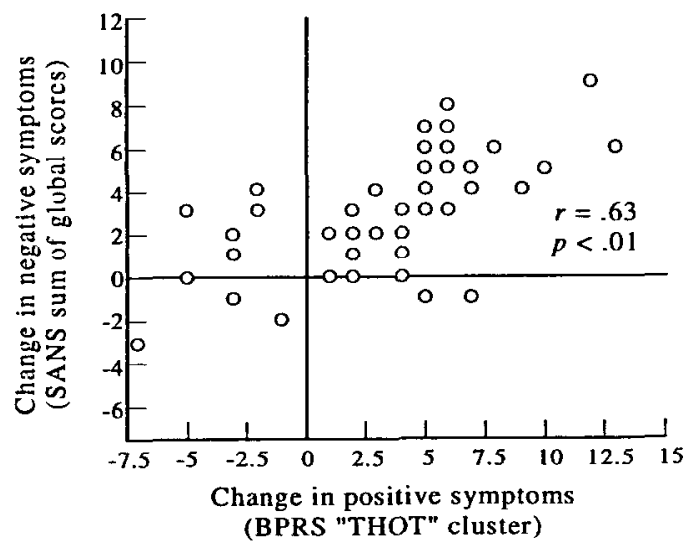

Figure 1 .

neuroleptic treatment immediately prior to the clozapine trial; consequently, withdrawal from conventional neuroleptics may have contributed to the observed changes in addition to the treatment with clozapine.

The correlation between change in positive symptoms and change in negative symptoms observed in this study differs from the findings of Meltzer (1991) who noted an absence of any such relationship. Although the precise reason for this discrepancy is unclear, it may partly be related to differences in sample characteristics and the instruments used to assess negative symptoms in these studies.

If confirmed, the covariance of positive and negative symptoms in the course of clozapine treatment could have important pathophysiological and treatment implications. Firstly, it suggests that clozapine does not differ from typical neuroleptics in this regard; i.e., there is one less aspect to its "unique" clinical profile that needs explanation. It is critical that clozapine's particular therapeutic profile be carefully defined as one attempts to better understand its hitherto unknown mechanism of action (Tandon \& Kane, 1993). Secondly, these data suggest that while clozapine is effective in the treatment of primary nonenduring negative symptoms (negative symptoms associated with positive symptoms sometimes called negative symptoms secondary to positive symptoms), its efficacy in treating deficit negative symptoms (Carpenter et al., 1988) is questionable. In fact, Breier et al. (1992) note that clozapinc appears to have a deleterious effect on deficit negative symptoms. Thirdly, the covariance of positive and negative symptoms during conventional and clozapine treatment indicates that common or related pathophysiological mechanisms may underly positive and primary nonenduring negative symptoms in schizophrenia (Tandon \& Greden, 1989).

How then does one explain the finding of a greater improvement in negative symptoms during treatment with clozapine than with conventional neuroleptics (Itoh et al., 1974; Kane et al., 1988; Meltzer, 1992)? It is well-known that negative symptoms are a heterogeneous 


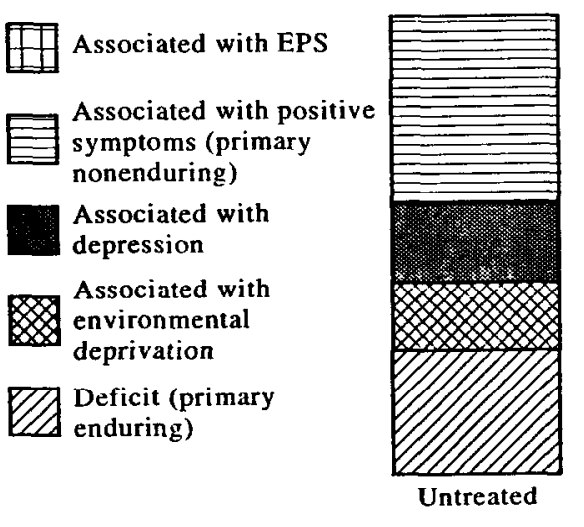

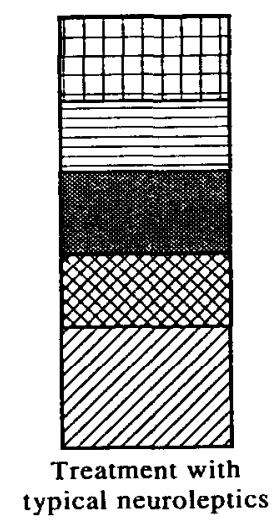

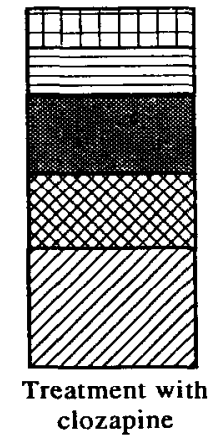

Figure 2.

construct and that negative symptoms (as measured) have multiple contributing factors (Carpenter et al., 1985, 1988; Moller, 1993; Tandon \& Greden, 1991). The apparent greater efficacy of clozapine in treating negative symptoms may be related to its greater efficacy in treating positive symptoms in otherwise treatment-refractory patients and because of its lesser propensity to cause EPS (Fig. 2). While the hypothesized differences in various components of negative symptoms under the three conditions depicted in Fig. 2 are somewhat speculative, they are consistent with the current conceptualization of ncgative symptoms in schizophrenia (Carpenter, 1991; Tandon \& Greden, 1991) and can explain observed differences in negative symptom severity under conditions of no treatment, classical neuroleptic treatment, and clozapine treatment.

In comparison to the drug-free state, as positive symptoms improve with neuroleptic treatment, that component of negative symptoms associated with positive symptoms improves as well. In otherwise neuroleptic-refractory patients, clozapine effects greater improvement in positive symptoms than conventional neuroleptics (Kane et al., 1988); one would expect a corresponding greater reduction in negative symptoms as well. While primary nonenduring negative symptoms decrease in the course of neuroleptic treatment, that component of negative symptoms reflecting extrapyramidal side-effects (EPS) increases. Since clozapine has a significantly lesser propensity to cause EPS than conventional neuroleptics (Kane et al., 1988; Lader, 1992; Meltzer, 1992), clozapine would be predicted to cause a lesser increase in this component of negative symptoms than typical neuroleptics. As graphically depicted in Fig. 2, one would expect the observation of a greater reduction in negative symptoms with clozapine than with conventional neuroleptics. In this depiction, components of negative symptoms related to deficit, environmental deprivation and depression are assumed to be constant in the untreated, typical neuroleptic and clozapine treatment conditions.

These data indicate that clozapine is similar to typical neuroleptics with regard to 
improvement in negative symptoms and their covariance with positive symptoms. In comparison to typical neuroleptics, the apparent greater efficacy of clozapine in treating negative symptoms may be related to its greater efficacy in treating positive symptoms in treatmentrefractory patients and its lower propensity to cause EPS.

\section{References}

American Psychiatric Association (1987). Diagnostic and statistical manual of mental disorders (3rd ed. rev.). Washington DC: Author.

Andreasen, N. C. (1983). Scale for the assessment of negative symptoms (SANS). Iowa City, University of Iowa.

Andreasen, N. C., Olsen, S. A., Dennert, J. W., \& Smith, M. R. (1982). Ventricular enlargement in schizophrenia: Relationship to positive and negative symptoms. American Journal of Psychiatry, 139, 297-302.

Breier, A., Buchanan, K. W., Kirkpatrick, B., Irish, D., Brandt, D., Carpenter, W. T. Jr. (1992). Clozapine in schizophrenic outpatients: Efficacy, longterm outcome, and predictors. Scientific Abstracts of the annual meeting of the American College of Neuropsychopharmacology, San Juan, 14-18 December 1992.

Breier, A., Wolkowitz, O. M., Doran, A. R., Roy, A., Buronow, J., Hommer, D. W., \& Pickar, D. (1987). Neuroleptic responsivity of positive and negative symptoms in schizophrenia. American Journal of Psychiatry, 144, 1549-1555.

Carpenter, W. T. Jr (1991) Psychopathology and common sense. Biological Psychiatry, 29, 735-737.

Carpenter, W. T. Jr., Heinrichs, D. W., \& Alphs, L. D. (1985). Treatment of negative symptoms. Schizophrenia Bulletin, 11, 440-452.

Carpenter, W. T. Jr, Heinrichs, D. W., \& Wagman, A. M. I. (1988). Deficit and nondeficit forms of schizophrenia: The concept. American Journal of Psychiatry, 145, 578-583.

Crow, T. J. (1980). Molecular pathology of schizophrenia: More than one disease process. British Medical Journal, 280, 66 68.

Endicott, J. \& Spitzer, R. L. (1978). A diagnostic interview: The schedule for affective disorders and schizophrenia. Archives of General Psychiatry, 35, 837-853.

Itoh, H., Miura, S., Yagi, G., Sakurai, S., \& Ohtsuka, N. (1977). Some methodological considerations for the clinical evaluation of neuroleptics - Comparative effects of clozapine and haloperidol on schizophrenics. Folia Psychiatrica et Neurologica, 31, 17-24.

van Kammen, D. P., Hommer, D. W., \& Malas, K. L. (1987). Effect of pimozide on positive and negative symptoms in schizophrenic patients: Are negative symptoms state dependent? Neuropsychobiology, 18, 113117.

Kane, J., Honigfeld, G., Singer, J., \& Meltzer, H. Y. (1988). Clozapine for the treatment-resistant schizophrenic: A double-blind comparison with chlorpromazine. Archives of General Psychiatry, 45, 789.796.

Lader, M. (1992). Clozapine A summary. British Journal of Psychiatry, 160 (Suppl. 17) 6566.

Meltzer, H. Y. (1990). Pharmacological treatment of negative symptoms. In J. F. Greden, \& R. Tandon (Eds), Negative schizophrenic symptoms: Pathophysiology and clinical implications (pp. 215-231). Washington DC: American Psychiatric Press.

Meltzer, H. Y. (1991). The effect of clozapine and other atypical antipsychotic drugs on negative symptoms. In A. Marneros, N. C. Andreasen, \& M. T. Tsuang (Eds), Negative versus positive schizophrenia (pp. 365-376). Berlin: Springer.

Meltzer, H. Y. (1992). Dimensions of outcome with clozapine. British Journal of Psychiatry 160 (Suppl. 17), 4653.

Moller, H.-J. (1993). Neuroleptic treatment of negative symptoms in schizophrenic patients. Efficacy problems and methodological difficulties. European Neuropsychopharmacology, 3, 1-11.

Overall, J. E., \& Gorham, D. R. (1962). Brief psychiatric rating scale (BPRS). Psychological Reports, 10, 799 812.

Spitzer, R. L., Endicott, J., \& Robins, E. (1978). Research diagnostic criteria: Rationale and reliability. Archives of General Psychiatry, 35, 773-782.

Tandon, R., Goldman, R. S., Goodson, J., \& Greden, J. F. (1990). Mutability and relationship between positive and negative symptoms during neuroleptic treatment. Biological Psychiatry, 27, 1323-1326.

Tandon, R., \& Greden, J. F. (1989). Cholinergic hyperactivity and negative schizophrenic symptoms. Archives of General Psychiatry, 46, 745-753. 
Tandon, R., \& Greden, J. F. (1991). Negative symptoms of schizophrenia: Need for conceptual clarity. Biological Psychiatry, 30, 321-325.

Tandon, R., \& Kane, J. M. (1993). Neuropharmacological basis for clozapine's unique profile. Archives of General Psychiatry, 50, 157159.

Tandon, R., Ribeiro, S. C. M., Goldman, R. S., DeQuardo, J. R., Goodson, J., \& Greden, J. F. (1993). Covariance of positive and negative symptoms during neuroleptic treatment in schizophrenia: A replication. Biological Psychiatry, 34, 495-497. 